\title{
Investigating the Influence of Stiffness on Decision Making for Haptic Interface Evaluation Development
}

\author{
Tomoe Ozeki \\ Electronics and Information Systems Engineering \\ Gifu University Graduate School of Engineering \\ Gifu, Japan \\ Email: mlab [AT] gifu-u.ac.jp
}

\author{
Tetsuya Mouri \\ Department of Mechanical Engineering \\ Gifu University \\ Gifu, Japan
}

\begin{abstract}
Sensation input very important information for human life. In order to explore the mechanism of perception caused by compliance (hardness or softness), it is necessary to collect and examine the phenomena that occur along the way, including physical reactions. The goal of our study is to investigate whether social perception and behavior are influenced by the sensation of a human finger using the haptic interface device. In this paper as the pretest of a haptic interface device, psychological experiments whether touching softball or hardball is influence on social perception and behavior of people are duplicated. STUDY1 using only the index finger showed that information of a reaction force acted on a human finger has no influence on others impression and has influence on social behavior. In STUDY2 with grasping the ball while collecting the surface electromyogram signals of the skin using SEMG sensors, the grasping ball's stiffness had influence on others impression and social behavior. This knowledge could be expected as a fundamental technology that improves the ease of use of a haptic interface and enables remote exchange of sensory information.
\end{abstract}

Keywords-component; compliance, stiffness, myoelectric signals, decision making, haptics interface

\section{INTRODUCTION (HEADING 1)}

The physical sensations such as touch and grasp give important information for a human to survive and to adaptive function [1][2][3]. And the physical sensation is thought that have an effect on feeling and mood, change human's social perception and behavior [4]. Haptic interface is a device that can give a human the sensation in response by movement [5]. So, haptic interface is expected as a tool that generates some feeling by touch and grasp and supports human decision making.

However haptic interface's performance is not shown enough as non-verbal communication devices such as touch and grasp. Because it is not many examples enough evaluated about informing the feeling of touch used haptic interface. Maisto et al. [6] evaluated two wearable haptic interfaces for the fingers in three AR scenarios by performance such as an error in tracing, completion time and total distance traveled by fingers. Springer \& Ferrier [7] introduced the design of a multifinger force-reflecting haptic interface device for teleoperation grasping and the evaluation of their device by the report which surface felt more like a "wall" or "rigid body". Frisoli et al. [8] developed the wearable haptic interface providing controllable force at the center of the user's righthand palm and reported the result of forces measured at the end-effector. Kawasaki and Mouri [9] shown five-fingered haptic interface robot and haptic interface can present force and tactile feeling to the five fingertips of the human hand and examined the effects in free space using five fingers by the responses of fingertip position, fingertip force. Haptic interface is usually an active device developed to reproduce synthetic environments exchanging information to others for real interaction to be active [10][11].

Many evaluations of haptics interface are performance of device force and error. In addition, there is subjective evaluation reported of participant's feelings when using haptic interface device. Participants feeling when using haptic interface is important information for participants decision making, but many subjective evaluations that participants report is very difficult to present that it is objective and consistent all case. To link device performance to human performance, it needs more systematic study that investigates more between the device and human not only mechanical function but also human function of physical, psychological and cognitive.

In social psychology studies, haptic sensations about touch have been discussed including investigation and experiment. Ackerman et al. [4] investigated that not only touching objects triggered the application of associated concept but also experience of touching specific objects elicit "haptic mindset". About the touch feeling of hard and soft, it was reported that touching has possible of influence on social cognitive processing because participants who sat in hard chairs judged the employee not more positive overall than did participants who sat in soft chairs. Slepian et al. [12] reported that grasping a softball or pressing softly on paper biased gender categorization toward "female" than grasping a hardball or pressing hard on the paper. They described that it is a possibility that people think males ("tough") and females ("tender") by through sensory feedback from handling hard (tough) or soft (tender) objects. Numazaki et al. [13] described also that participants who grasping soft rubber ball felt 
positive-female to a fictional person created by experimenter than participants who grasp hard wire ball. Thus, touch feeling of hardness and softness is the possibility that can change social perception such as participants judged other's character (positive/negative and female/male). As a result, a human might change their behavior caused by changing social perception from touching something. In order to investigate it, we think that an experiment that can quantitatively adjust compliance more accurate than an unstable stimulus like softball which cannot expect strict consistency in quality is necessary. In addition, we suggest that examine whether change behavior such as prosociality as a result of changing social perception.

This paper focus is to be clear the changes and relationships in human emotions and behaviors caused by softness and hardness for developing an evaluation of haptics interface system. In the impression survey conducted while feeling rubber balls of different hardness, it is known that the person who answered while touching a non-hardball has a feminine impression on the person mentioned in the survey [8][9]. However, no information has been collected on whether or not they both feel hardness. Furthermore, we have not been able to fully examine whether the results of impression changes and donation behavior are related to hardness. STUDY1 examines whether the result is affected when grasping the hardness of the ball and when touching with one finger. STUDY2 examine whether had influence on the result in psychological experiments that participants who were measured their feeling of hardness or softness by using sEMG.

This study was both conducted in accordance with the recommendations of the Ethical Guidelines for Medical and Health Research Involving Human Subjects provided by the Ministry of Education, Culture, Sports, Science, and Technology and the Ministry of Health, Labor, and Welfare in Japan with written informed consent from all subjects. All subjects gave written informed consent in accordance with the Declaration of Helsinki. The protocol was approved by the Medical Review Board of Gifu University Graduate School of Medicine.

\section{STUDY1}

Slepian et al.[12] and Numazaki et al.[13] have examined whether human cognition could be embodied by physical sensations and behavior by hardness using softball and hardball which participants grasp using the entire hand in experiments. We conducted experiment with only one finger of the participant in order to confirm whether human cognition changes due to hardness was reproduced even on a haptic interface that can present force sense for each finger did. STUDY1 investigates whether the participants change their judgment about others impression based on the touch of hardness or softness [17]. In addition, we examined that influence on their decision by the degree of stiffness of balls in the dictator game. So that, we duplicate a part of Numazaki et al.[9] that used hardball, using dominant hand, how to touch the ball and questionnaire that can be answered by only mouse control.

\section{A. Participants}

Twenty college students (70\% male, 30\% Female) are assigned to select group of a hard or softball at random (hardball group $n=10$, softball group $n=10$ (Age $M=20.55$, $\mathrm{SD}=1.83$ ). Participants were recruited and informed that they would be given a reward by participating in the experiment and submitting questionnaire. All the participants who finished all the work for the experiment got a book card of 500 JPY. This study was approved by the Medical Review Board of Gifu University Graduate School of Medicine, and all participants gave written informed consent before participation.

\section{B. Supplements}

Balls used for softness-hardness manipulation were soft tennis ball under softball conditions (manufactured by CALFLEX), wire balls under the condition of hardballs (Figure 1). The size of softball and hardball are not exactly the same, but we prepared as equal as possible (weight: softball $=30 \mathrm{~g}$, hardball $=20 \mathrm{~g}$; diameter: softball and hardball $=66 \mathrm{~mm})$. In addition, we measured the stiffness of softball and hardball and confirmed the objective numerical values (stiffness: softball = $0.27[\mathrm{~N} / \mathrm{mm}]$, hardball $=0.71[\mathrm{~N} / \mathrm{mm}])$ (Figure 2). The ball was kept in the laboratory for more than 60 minutes before the experiment so that the temperature was the same. The laboratory temperature was kept at 23 degrees Celsius. However, softballs and hardballs used in the experiments are made of different materials and might be affected by temperature and touch. Therefore, participants wore the gloves made of non-breathable material (manufactured by MEDILINE; MDS192076J) to be made feeling the temperature and touch as less as possible.

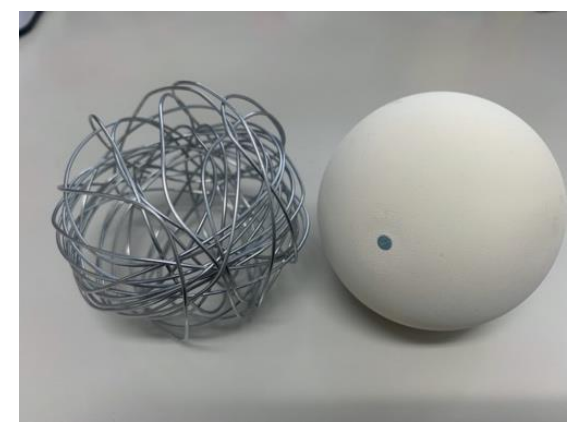

Figure 1. Hardball(left) and Softball(right) in STUDY1

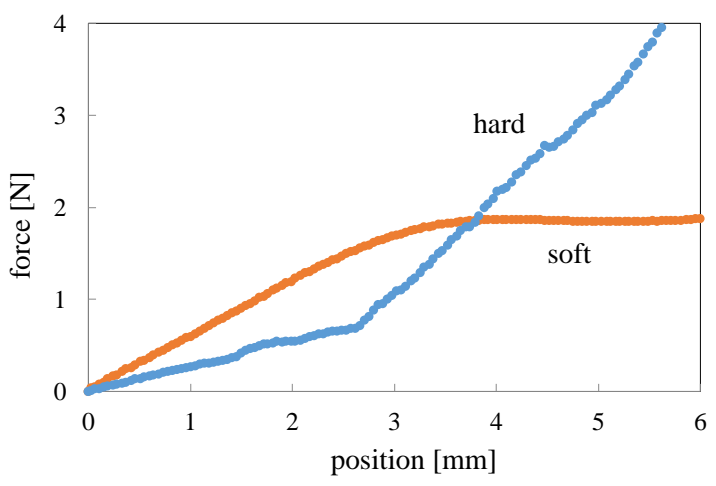

Figure 2. Stiffness condition in STUDY1 


\section{Experimental design}

This experiment was conducted in the form of individual experiments by female experimenters under the name "the effect of physical disability on stress" in the same way as Numazaki et al. [13] excepted dictator games. The dictator game is an economic game that is designed by the dictator who can decide how much of the initial pie to the recipient [15]. This game is popular to show altruistic behavior with participant's offering. This game is popularly reasoned that can investigate whether the participant has altruistic behavior by a number of offering coins to the recipient. The differences from Numazaki et al.[13] experiment was that they used only one finger instead of holding the ball with their hands, and added a dictator game to make it easier to see the changes in human behavior. Participants were told the cover stories that they focused on inconvenience related to arms.
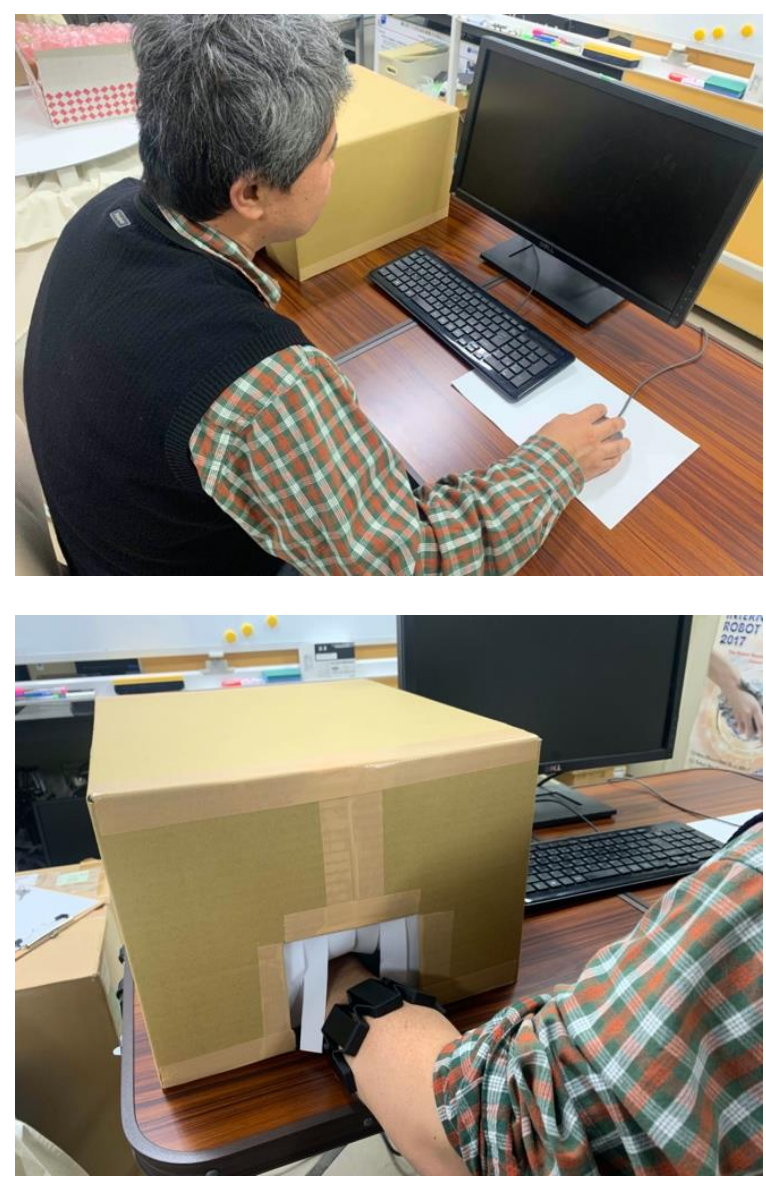

Figure 3. Image of experiment

\section{Procedure}

Participants were asked by the experimenter which the dominant hand. Participant's dominant hand was worn the glove made of non-breathable material and were instructed that put in the box made of cardboard boxes (soft tennis balls for soft condition participants; wire balls for hard condition participants). At that time, the participants were asked to hold down with the index finger to feel hardness and softness. We prepared a questionnaire that can be answered by only mouse control. Participants were explained that the experimenter would ask to answer the classification task and the questionnaire on the web using the mouse by the opposite hand in the state of dominant hand unable to use from the elbow. After that, participants answered whether they read and agree with the experiment consent documents on the web (Figure 3 ).

Firstly, participants who answered that they agreed with the experiment consent documents conducted a name discrimination task on the web. We presented the person's name on the screen, letting the participant judge whether it was the name of a male or a female name. The names used in the experiments of Numazaki et al. [13] were randomly presented in our experiment ( female name: Ayaka, Aya, Sawako, Saori, Miho, Mai, Aiko, male name: Shouta, Kenta, Harukazu, Daiki, Yuuta, Kazuya, Daisuke, gender-free names: Makoto, Chiaki, Rei, Yu, Hikaru, Kei, Yuuki).

Secondly, a dictator game was conducted. This game examined whether change behavior such as prosociality as a result of changing social perception. We asked to participants deciding what number of coins offer to charity. Participants were informed on the web that experimenter would provide 1000 JPY(ten 100 JPY coins) after the experiment. At that time, the participants were asked to select the use of 1000 JPY from the choices. At that time, the participants were asked about options for 1000 JPY use; Please decide to get your number of coins from 0 to $1000 \mathrm{JPY}$ and please donate the remainder to the donating organization? In this task participants only answered on the web, they did not handle actual coins.

Thirdly, participants responded to the question of the SESRA-S; a 15-item short-form of the Scale of Egalitarian Sex Role Attitudes [16].

Finally, as a "survey on impression formation", we showed participants a profile of a female university student in Tokyo and asked about their impression. After presenting this profile, we gave participant an impression assessment questionnaire. The answers to these questions were prepared using 7-point Likert scale. Participants reported to the experimenter after completing the all tasks.

\section{E. Result}

We used the analysis method of Numazaki et al [13] excepted dictator games. For each dependent variable, the score of SESRA-S was standardized and analyzed by a general linear model of the ball (softness vs. hardness) and sexual role view (standardization score of SESRA-S).

Participants classified seven names used for men and seven names used for women into sexes that almost all supposed. In both males and females, 19 out of 20 participants classified all seven names, and the remaining 1 classified as sexes assuming six names. Regarding the seven names used for both men and women, we determined the number judged to be male and analyzed by using a general linear model of the ball (softness vs. hardness) and sexual role view (SESRA-S). The main effect 
of the ball with which it had was not significant $(\mathrm{F}(2,17)=0$. $67, \mathrm{~ns})$.

Secondly, the hardness condition was number of coins offered to charity more than the softness condition in the dictator game $(\mathrm{F}(2,17)=5.58, \mathrm{p}<.05)$ (Figure 4).

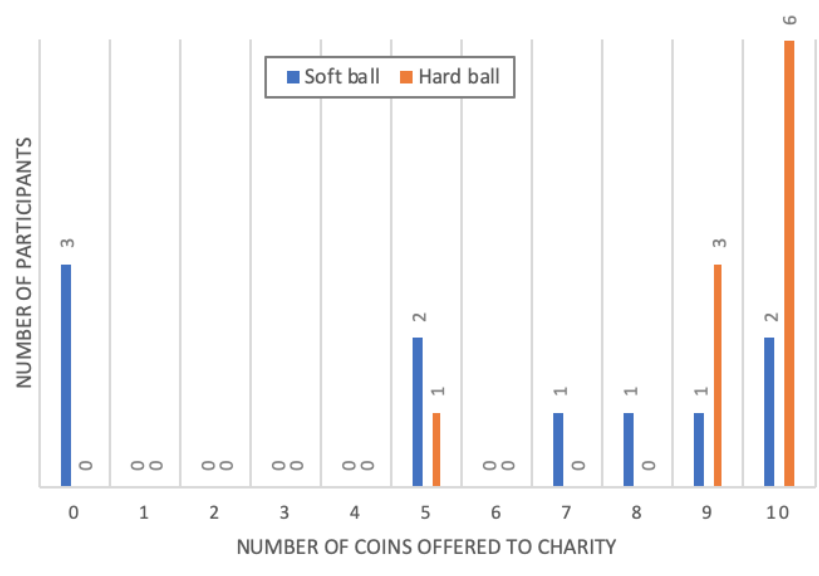

Figure 4. Result of dictator game

Thirdly, the analysis was carried out by the general linear model of the ball's stiffness (softness vs. hardness) and sexual role view (SESRA-S) for each characteristic. There was no significant related to the ball's stiffness and the sex view roll $(\mathrm{F}$ $(2,17)=2.711, \mathrm{~ns})$.

Finally, the profile of a female college student was no effect from the ball's stiffness (softness vs. hardness) and sexual role view $($ SESRA-S $)(\mathrm{F}(2,17)=0.67, \mathrm{~ns})$.

\section{F. Discussion}

STUDY1 did not duplicate the results of Numazaki et al [13]. Therefore, there was difference in touch effect of real supplements between feeling by one finger and feeling by grasping hands. There was a significant difference in the dictator game which does not use actual coin by the ball condition. This result indicates that social perception might be changed by touching the ball with index finger. We must consider enough taking of this result to expand for designing of haptic interface.

Score of name discrimination task did not influence by touching softball and hardball with index finger. Participants discriminated a man or female properly by name is shown on display. However, participants report of gender was inconsistently when showing a gender-free name on display. Our result using only index finger duplicated the results of Numazaki et al [13]. Hardness and softness might not affect gender judgment by name. However, Numazaki et al. [13] predicted that some names used at experiment were the cases of same as participant's friends. It is necessary to carry out additional tests not only about the number of fingers touching the ball but also to determine whether hardness or softness is affected.

The score of dictator game during answered questionnaire on Web showed possibility that the hardness condition was more selfish. The hardness or softness of the ball was related significantly the coin's amount of offer. It is possible that touch hardness of ball has the effect of decision making. However, it might influence number of offered coins caused by no touching coins. If touch of hardness is influenced by people decision making of sharing coins, haptic interface will give people behavior change. So, it must carefully investigate more whether there is the effect of changing people's behavior.

There was no relationship between ball hardness and softness in male and female characteristics positive and negative evaluations. Numazaki et al. [13] results reported that grasping softballs valued female positive characteristics more than grasping hardballs. The results of touching the ball with one finger did not duplicate the result of holding the ball with his hand. The task of showing the profile of a female college student was no effect from softball and hardball. Participants in the hardball group had a higher average value in the profile than softball. However, it is no significant difference between softball score and hardball score. This result did not duplicate Numazaki et al [13]. It is possible that it has been caused by touching with a single finger instead of grasping the ball. Therefore, it is necessary to carefully consider the shapes of fingers and hands when presenting hardness and softness with the haptics interface.

There are limits to our interpretation. We made the hardball with handmade using the wire referring to Numazaki et al [13]. It was possibility that the thickness of the wire forming the ball and the method of wrapping is different, so the result could not be reproduced to perfection. Therefore, it can be expected that the temperature of the wire ball will be different. The possibility that the sensible temperature of the ball affects social impression and behavior is also mentioned by Numazaki et al [13]. And not having grasped but having felt hardness and softness by pushing with one finger might have caused different results. The structure of the wire ball also changes the way of deformation, depending on the side touched with a single finger. Therefore, after examining enough whether these results are affected by the material, temperature, object structure, and touching method of the part touched directly, it should consider implementing it on the haptic interface.

\section{STUDY2}

In STUDY2, while collecting changes in the surface electromyogram signals of the skin using sEMG sensors, a psychological experiment is conducted on the hardness of the wearer and examines whether it can be interpreted until decision-making process and action. STUDY1 performed an experiment by touching a rubber ball and a wire ball with one finger, but the result was different from Numazaki et al [13]. It was not possible to identify whether the different causes were the difference in touching style or the effect of the ball. So that, STUDY2 focuses on whether the impression of others and changes of behavior occur by hand touching the ball of same material whose hardness and softness are measured firmly [18]. Participants were confirmed whether have been grasping the ball during the experiment by surface electromyogram (sEMG). 


\section{A. Participants}

Twelve participants (11 males, 1 not male) were assigned to group of a hard or softball selected at random (hardball group $\mathrm{n}$ $=6$, softball group $\mathrm{n}=6$; Age $\mathrm{M}=24.25, \mathrm{SD}=7.91$ ). Participants were recruited and informed that they would be given a reward by participating in the experiment and submitting questionnaire. All the participants who finished all the work for the experiment got a book card of 500 JPY. This study was approved by the Medical Review Board of Gifu University Graduate School of Medicine, and all participants gave written informed consent before participation.

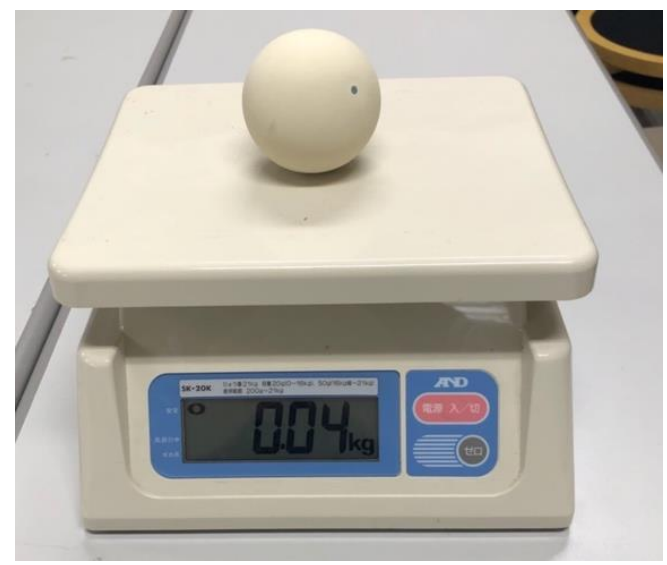

Figure 5. Softball in STUDY2

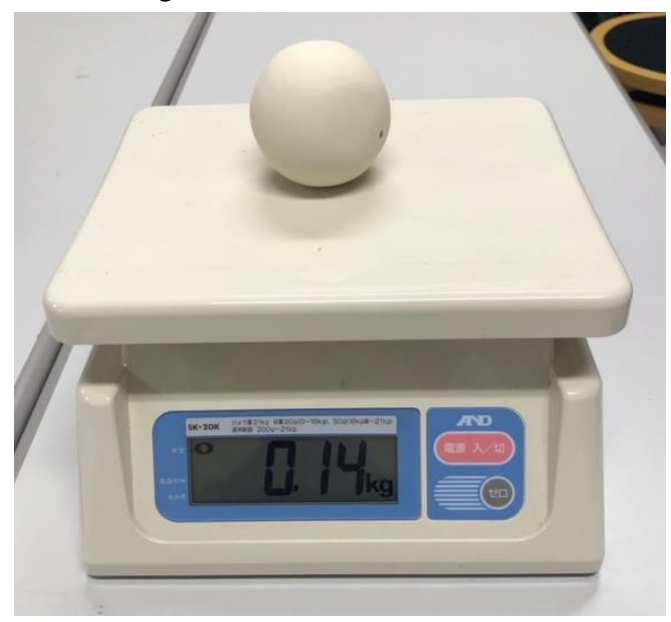

Figure 6. Hardball in STUDY2

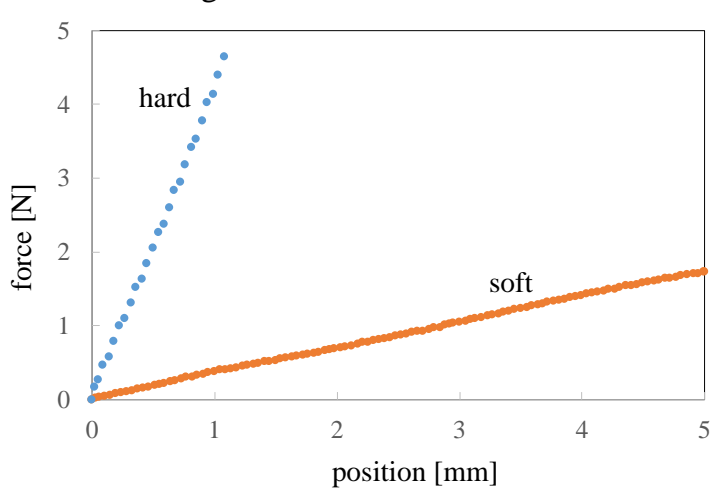

Figure 7. Stiffness condition in STUDY2

\section{B. Supplements}

Balls used for softness-hardness manipulation were soft tennis ball under softball conditions (Figure 5)., soft tennis ball hardened by injecting silicon under the condition of hardballs (Figure 6). Both rubber balls are originally the same product. The size of softball and hardball are not exactly the same, but we prepared as equal as possible (weight: softball $=40 \mathrm{~g}$, hardball $=140 \mathrm{~g} ;$ diameter: softball and hardball $=62 \mathrm{~mm})$. In addition, we measured the stiffness of balls (softball and hardball), and confirmed the objective numerical values (stiffness: softball $=0.35[\mathrm{~N} / \mathrm{mm}]$, hardball $=4.24[\mathrm{~N} / \mathrm{mm}]$ ) (Figure 7). The ball was kept in the laboratory for more than 60 minutes before the experiment so that the temperature was the same. The laboratory temperature was kept at 23 degrees Celsius.

\section{Experimental design}

This experiment was conducted in the form of individual experiments in the same way as STUDY1 excepted holding ball by the opposite of dominant hand. Participants have conducted the questionnaire on the web using the mouse by the dominant hand.

\section{Procedure}

Participants were asked by the experimenter which hand is the dominant hand. Participant's the opposite arm of dominant hand was worn sEMG and were instructed that putted in the box made of cardboard boxes (soft tennis balls for softness condition participants; hard tennis balls for hardness condition participants). Subsequent experimental procedures were performed in the same as STUDY1.

\section{E. Result}

Participants classified seven names used for men and seven names used for women into sexes that almost all supposed. Regarding the seven names used for both men and women, we determined the number judged to be male and analyzed by using a general linear model of the ball (softness vs. hardness) and sexual role view (SESRA-S). The main effect of the ball with which it had was not significant $(\mathrm{F}(2,9)=.03$, ns $)$.

In the second task of the dictator game, the ball's stiffness (softness or hardness) was related significantly to the number of coins offered to charity $(\mathrm{F}(2,9)=5.53, \mathrm{p}<.05)$ (Figure 8).

In third task, analysis was carried out by the general linear model of the ball (softness vs. hardness) and sexual role view (SESRA-S) for each characteristic. There was no significance relate between the ball's stiffness and the sex view roll (F (2, $17)=2.711$, ns). Compared to the softness condition, the hardness condition had the impression that the stimulant person had a masculine negative characteristic $(\mathrm{p}<.05)$ (M-Negative).

Lastly, showing the profile of a female university student was a statistically related significance between the ball (softness vs. hardness) and sexual role view (SESRA-S) (F (2, $9)=8.59, p<.01)$. Participants in the hardball group had a higher average value with favorable in the profile. 


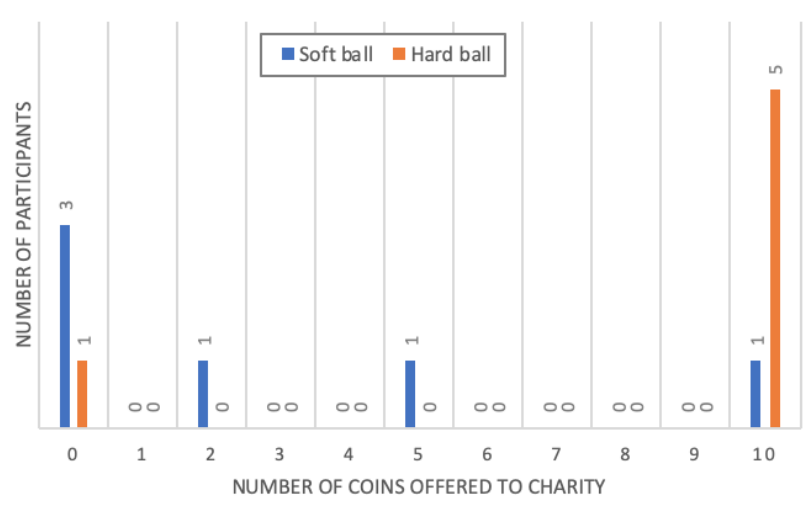

Figure 8. Result of dictator game

The measurement results of sEMG are shown in Figure 9 and Figure 10. Participants were able to confirm that they were holding the ball throughout the experiment.

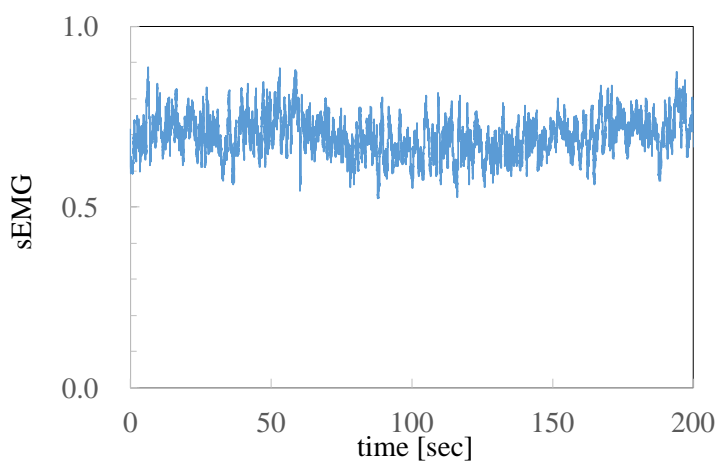

Figure 9. sEMG of softness condition

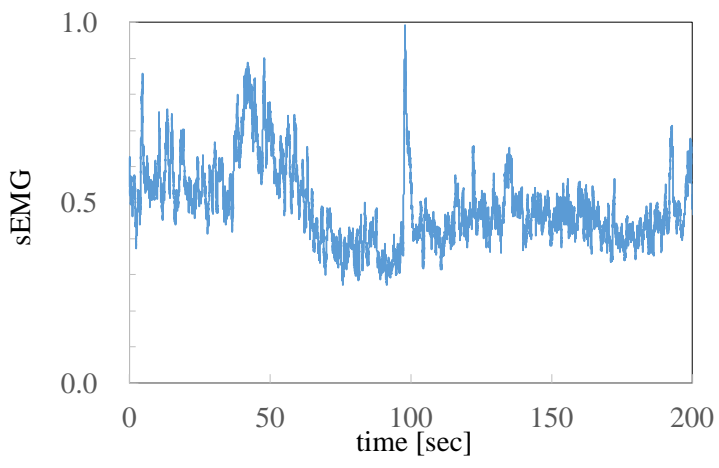

Figure 10. sEMG of hardness condition

\section{F. Discussion}

STUDY2 duplicated the part of results of Numazaki et al [13] of same effect by grasping hand the ball. There was a significant difference in the dictator game which does not use actual coin by the ball condition, as same result of STUDY1 with touching one finger. This result indicates that graspping the ball whit hand might be changed social perception and decision than more touching the ball with index finger. The result of STUDY2 obtained by focusing on hardness suggest that the feeling of hardness and softness may change into impressions and prosocial behavior.

The task of name discrimination in STUDY2 also did not have influence by touching softball and hardball with index finger. Our results supported the results of Numazaki et al [13]. As mentioned in STUDY1, Japanese gender-free names might have been influenced by other factors, such as possibility participant having the same name friends. Therefore, it is necessary to retest the survey method.

The result of dictator game showed also possibility that the hardness condition was more selfish. In STUDY2, hardballs were only paid for charity or not paid at all. The softballs were different in the number of coins to pay. These results suggest that stiffness might have some effect on prosocial behavior.

There was a little relationship between ball hardness and softness in male and female characteristics positive and negative evaluations. The softballs condition scored higher on male negative characteristics presented female student profile than with hardballs condition. Numazaki et al [13]. showed that grasping a softball condition appreciate their female positive characteristics more than grasping a hardball condition. In STUDY2, the grasping hardball condition valued both female positive characteristics and male negative characteristics higher than the grasping softball. In addition, the female student's profile was significantly favored when grasping softball more than grasping hardball. These are the opposite result from Numazaki et al [13]. In our experiments, the hardball was a ball that had been adjusted to the same temperature by injecting silicon into the same rubber ball as the softball condition. It is different from the hardball made of wire used by Numazaki et al.[13], So it might have influenced on evaluations. However, it necessary to confirmed additional tests because STUDY2 has 10 participants, which is half of 21 Numazaki's participants.

\section{GENERAL DISCUSSION}

Our studies duplicated the part of results of Numazaki et al [13]. In STUDY1 with touching one finger, there was no influence on other's impression, but there was a significant difference in the dictator game by the ball condition. The result of STUDY2 obtained by focusing on hardness suggests that the feeling of hardness and softness may change into impressions and prosocial behavior. This result indicates that might be changed social perception and behavior by how to touch the ball.

The task of name discrimination in STUDY1 and STUDY2 also did not have influence by touching softball and hardball with index finger. Our results supported the results of Numazaki et al [13]. However, the experiments of Slepian et al. [8] were significantly related to the stiffness of the ball and the outcome of the gender assignment task with a controlled face photo. This may be due to differences between photos and names and cultural differences between Japan and other countries. Therefore, it is necessary to conduct a more detailed 
investigation to determine whether the effect of hardness is a universal response.

The results of dictator game showed also possibility that the hardness condition was more selfish. The hardness or softness of the ball was related significantly the coin's amount of offer. In both STUDY1 and STUDY2, participants who touched a hardball offered many coins to charity, and the number of players who played all 10 coins was more than twice as many as those who touched a softball. This result might support the result of Ackerman et al [4]. However, our results might be influence caused by no touching coins. According to the dictator game Meta-Analysis, it was reported that the offer was higher when using real money [15]. In order to be clear these effects, it is necessary to test both in terms of actual money and hardness. If touch of hardness influenced people's decision making of sharing coins, giving stiffness by haptic interface might influence people's behavior change too.

The result of STUDY1 was no relationship between stiffness of the ball in male and female characteristics positive and negative evaluations. On the other hand, the result of STUDY 2 could be found a few relationships. Grasping the hardball was influenced on valued evaluation of male negative characteristics more than grasping softballs. However, our result of STUDY2 was not same Numazaki et al [13]. At least, touching the ball with one finger did not influence that changing impression of female student profile less than holding the ball with his hand. Feeling stiffness by grasping the ball might affect the impression of female student's profile. Even in the condition of a hardball, it seems that effect is different for a wire ball and a rubber ball containing silicon. There are limits to our interpretation. So that it is necessarily to carefully follow up on these differences of results.

\section{CONCLUSION}

This paper reproduces the difference in the impression of a person by holding a softball and a hardball. And it was possible to measure by sEMG how to hold the ball reliably during the experiment. It was found that touching a hardball might increase prosocial behavior more than touching a softball. If the difference in stiffness affects impressions and social behavior, the degree of stiffness that may arise can be used as an evaluation axis. In order to develop evaluation, it is necessary to confirm the details of these factors and the measurement transition of myoelectricity.

We expect that these investigations would be useful as a fundamental technology that improves the ease of use of a haptic interface and enables remote exchange of sensory mechanism.

\section{ACKNOWLEDGMENT}

We would like to thank Professor Naoki Mizuno Nagoya Institute of Technology. Hidemi Ogasawara and Associate Professor Takafumi Tsuchiya Chukyo University were given insightful comments and suggestions.

\section{REFERENCES}

[1] Craig, J. C., \& Rollman, G. B. (1999). Somesthesis. Annual review of psychology, 50(1), 305-331.

[2] Lederman, S. J., \& Klatzky, R. L. (2009). Haptic perception: A tutorial. Attention, Perception, \& Psychophysics, 71(7), 1439-1459.

[3] Kappers, A. M., \& Bergmann Tiest, W. M. (2013). Haptic perception. Wiley Interdisciplinary Reviews: Cognitive Science, 4(4), 357-374.

[4] Ackerman, J. M., Nocera, C. C., \& Bargh, J. A. (2010). Incidental haptic sensations influence social judgments and decisions. Science, 328(5986), 1712-1715.

[5] Hayward, V., Astley, O. R., Cruz-Hernandez, M., Grant, D., \& RoblesDe-La-Torre, G. (2004). Haptic interfaces and devices. Sensor Review, 24(1), 16-29.

[6] Maisto, M., Pacchierotti, C., Chinello, F., Salvietti, G., De Luca, A., \& Prattichizzo, D. (2017). Evaluation of wearable haptic systems for the fingers in augmented reality applications. IEEE transactions on haptics, 10(4), 511-522.

[7] Springer, S. L., \& Ferrier, N. J. (2002). Design and control of a forcereflecting haptic interface for teleoperational grasping. Journal of Mechanical Design, 124(2), 277-283.

[8] Frisoli, A., Rocchi, F., Marcheschi, S., Dettori, A., Salsedo, F., \& Bergamasco, M. (2005, March). A new force-feedback arm exoskeleton for haptic interaction in virtual environments. In First Joint Eurohaptics Conference and Symposium on Haptic Interfaces for Virtual Environment and Teleoperator Systems. World Haptics Conference (pp. 195-201). IEEE.

[9] Kawasaki, H., \& Mouri, T. (2007). Design and control of five-fingered haptic interface opposite to human hand. IEEE Transactions on robotics, 23(5), 909-918.

[10] Tan, H. Z., Srinivasan, M. A., Eberman, B., \& Cheng, B. (1994). Human factors for the design of force-reflecting haptic interfaces. Dynamic Systems and Control, 55(1), 353-359.

[11] Bos, R. A., Haarman, C. J., Stortelder, T., Nizamis, K., Herder, J. L., Stienen, A. H., \& Plettenburg, D. H. (2016). A structured overview of trends and technologies used in dynamic hand orthoses. Journal of neuroengineering and rehabilitation, 13(1), 62 .

[12] Slepian, M. L., Weisbuch, M., Rule, N. O., \& Ambady, N. (2011). Tough and tender: Embodied categorization of gender. Psychological science, 22(1), 26-28.

[13] Numazaki, M., Matsuzaki, K., \& Hanta, K. (2016). The effects of haptic experience on interpersonal perception and self-perception. The Japanese Journal of Experimental Social Psychology. 2016, Vol. 55, No. 2, 119-129. DOI:10.2130/jjesp.si1-4

[14] Nakata, A., Shiomi, M., Kanbara, M., \& Hagita, N. (2017). Effect of being Hugged by a Robot for a Prosocial Behavior Request. IPSJ Interaction 2017. 45-52

[15] Engel, C. (2011). Dictator games: A meta study. Experimental Economics, 14(4), 583-610.

[16] Suzuki, A. (1994). Construction of a short-form of the scale of egalitarian sex role attitudes (SESRA-S). Shinrigaku kenkyu: The Japanese journal of psychology, 65(1), 34-41.

[17] Ozeki, T., \& Mouri, T. (2019). Behavior Change Based on Stiffness for Haptic Interface. Proceeding of International Conference on Intelligent Robots and Systems 2019. 861.

[18] Ozeki, T., \& Mouri, T. (2020). An attempt to investigate the relationship between feeling of the hardness of an object and decision making by using myoelectric signals. Proceeding of International Symposium on Artificial Life and Rovotics 2020. [to be published] 